\title{
APLICAÇÃO WEB PARA APOIAR AS ATIVIDADES EXTENSIONISTAS DA ESCOLA DE MÚSICA “O SOM DO CERRADO”
}

\author{
Igor Lucio Rocha Alves ${ }^{1}$
}

ORCID: 0000-0003-4697-3804

WALTER HENRIQUe Silva ${ }^{2}$

ORCID: 0000-0002-8630-5977

Guilherme Vinhal Nunes ${ }^{3}$

ORCID: 0000-0001-5026-6040

Larissa Ferreira Rodrigues ${ }^{4}$

ORCID: 0000-0001-8947-9182

Paulo Nogueira Andrade Godoi ${ }^{5}$

ORCID: 0000-0002-5932-1525

Estudante do curso de Sistemas de Informação da Universidade Federal de Viçosa - Campus Rio Paranaíba (UFV-CRP) e desenvolvedor front-end na Connectronic. Endereço: Rodovia MG-23o, km 7, Rio Paranaíba/MG, Brasil. Caixa Postal: 22. E-mail: igor.lucio@ufv.br.

2 Estudante do curso de Sistemas de Informação da Universidade Federal de Viçosa - Campus Rio Paranaíba (UFV-CRP), desenvolvedor front-end e back-end, entusiasta em Ciência de Dados e contribuidor open source.Endereço: Rodovia MG-23o, km 7, Rio Paranaíba/MG, Brasil. Caixa Postal: 22. E-mail: (walter.silva@ufv.br).

3 Estudante do curso de Agronomia da Universidade Federal de Viçosa - Campus Rio Paranaíba (UFV-

-CRP) e Técnico em Eletrônica pelo SENAI Patos de Minas. Endereço: Rodovia MG-230, km 7, Rio Paranaíba/MG, Brasil. Caixa Postal: 22 E-mail: (guilherme.vinhal@ufv.br).

4 Mestre em Ciência da Computação pela Universidade Federal de Viçosa (UFV) e graduada em Sistemas de Informação pela Universidade Federal de Viçosa, Campus Rio Paranaíba (UFV-CRP). Atualmente é docente na UFV-CRP e seus principais interesses de pesquisa incluem: Aprendizado de Máquina, Visão Computacional e Processamento de Imagem. Endereço: Rodovia MG-23o, km 7, Rio Paranaíba/MG, Brasil. Caixa Postal: 22. Telefone: (34) 3855-9367. E-mail: (larissa.f.rodrigues@ufv.br).

5 Mestre em Controladoria e Contabilidade Estratégica pelo Centro Universitário FECAP, especialista em Contabilidade, Auditoria e Controladoria pela PUC Campinas e bacharel em Administração pela PUC Campinas. Atualmente é docente na Universidade Federal de Viçosa, Campus Rio Paranaíba (UFV-CRP) e coordenador da Escola de Música "O Som do Cerrado". Endereço: Rodovia MG-23o, km 7, Rio Paranaíba/MG, Brasil. Caixa Postal: 22. Telefone: (34) 3855-9486. E-mail: (paulo.godoi@ufv.br). 
Resumo: A Escola de Música “O Som do Cerrado” foi fundada em 2015 e ensina teoria e prática musical aplicada a diversos instrumentos para a comunidade interna e externa à Universidade. Entretanto, as atividades extensionistas realizadas não são divulgadas no âmbito digital e a gestão de atividades, documentos e fluxo de trabalho são feitos de forma manual, sendo uma tarefa bastante dispendiosa. Dessa forma, este projeto de extensão tem o objetivo de aplicar Tecnologia da Informação para apoiar as atividades extensionistas da Escola de Música. Foi desenvolvida uma aplicação web utilizando ferramentas gratuitas e com etapas de desenvolvimento baseadas no SCRUM e Kanban. A aplicação web trouxe modernização para a gestão de documentos e fluxo de trabalho da escola de música e recursos necessários para a divulgação das atividades extensionistas em meio digital.

Palavras-chave: Escola de música. Aplicação web. Tecnologia da Informação.

\title{
WEB APPLICATION TO SUPPORT EXTENSIONIST ACTIVITIES OF THE “SOM DO CERRADO" MUSIC SCHOOL
}

\begin{abstract}
O Som do Cerrado" Music School was founded in 2015 and teaches music theory and practice applied to various instruments for the University internal and external community. However, the extension activities performed are not published online; also, managing activities, documents, and workflow is done manually and is an expensive task. Therefore, this extension project aims at applying Information Technology to support the extensionists activities of the School of Music. We developed a web application using free tools with development steps based on SCRUM and Kanban. The web application provides modernization for document management and workflow of the music school and resources needed for the dissemination of extension activities online.
\end{abstract}

Keywords: Music school. Web application. Information Technology.

\section{FPLICACIÓN WEB PARA APOYAR ACTIVIDADES EXTENSIONISTAS DE LA ESCUELA DE MÚSICA “SOM DO CERRADO”}

Resumen: La Escuela de Música "O Som do Cerrado" fue fundada en 2015 y enseña teoría y práctica musical aplicada a varios instrumentos para la comunidad interna y externa de la Universidad. Sin embargo, las actividades de extensión realizadas no se publican en línea; además, la gestión de actividades, documentos y flujo de trabajo se realiza manualmente y es una tarea cara. Por lo tanto, este proyecto de extensión tiene como objetivo aplicar la Tecnología de la Información para apoyar las actividades extensionistas de la Escuela de Música. Se desarrolló una aplicación web utilizando herramientas gratuitas y desarrollo de software basados en SCRUM y Kanban. La aplicación web proporcionó modernización para la gestión de documentos y el flujo de trabajo de la escuela de música y los recursos necesarios para la difusión de actividades de extensión en medios digitales.

Palabras claves: Escuela de musica. Aplicación web. Tecnología de la Información. 


\section{INTRODUÇÃO}

A música é reconhecida como uma linguagem universal, sendo a principal arte presente em variadas culturas e na história da humanidade desde as primeiras civilizações (DA CUNHA, 2016). De acordo com pesquisas realizadas anteriormente, a música tem forte influência sobre a sociedade, pois cada indivíduo traz dentro de si a harmonia que rege seus pensamentos, emoções, saúde e todo o seu bem estar (SCHMIDT, 2005; SPYCHIGER et al., 2009; HALLAM, 2010; IWASAKI et al. 2010; MAWANG et al. 2019).

Entretanto, a maioria dos estudos presentes na literatura não investigam a importância do ensino de música em instituições de nível superior. Com o intuito de contribuir com pesquisas nesse cenário, desde 2011, são realizadas atividades musicais na Universidade. As atividades desenvolvidas foram ampliadas e no ano de 2015 foi fundada a Escola de Música "O Som do Cerrado", permitindo a inserção da cultura musical no cotidiano dos alunos por meio de atividades de teoria e prática musical aplicada aos variados instrumentos musicais, tais como: flauta, violão, guitarra, contrabaixo, teclado, bateria e saxofone. Também são oferecidos treinamentos para apresentações em público e são realizadas apresentações musicais para a comunidade em geral (em eventos acadêmicos e regionais).

Observa-se que a gestão de atividades, documentos e fluxo de trabalho da Escola de Música "O Som do Cerrado" são realizadas de forma manual e em meio físico. No entanto, o avanço exponencial da tecnologia nos últimos anos tornou o armazenamento e gerenciamento de documentos em meio físico obsoleto e dispendioso. Diante disso, o uso da Tecnologia da Informação (TI) apresenta-se como uma alternativa promissora, pois permite aprimorar operações e processos por meio do uso de computadores, softwares e hardwares (LAURINDO, 2001). Assim, facilita o trabalho realizado e gera uma sensibilização para mudança de hábito ao substituir o documento em papel para o meio digital.

Neste contexto, este trabalho tem como objetivo principal desenvolver uma aplicação Web para divulgar as atividades extensionistas realizadas pela Escola de Música "O Som do Cerrado" no âmbito digital e também promover a modernização da gestão de documentos e do fluxo de trabalho.

O presente trabalho apresenta uma aplicação web que foi desenvolvida utilizando ferramentas gratuitas e com etapas de desenvolvimento ágil baseadas no SCRUM e Kanban. Também foi criada a identidade visual da Escola de Música com os elementos visuais que comunicam e representam seus valores. Com essa aplicação 
foram geradas oportunidades de maior visibilidade com o propósito de difundir arte, cultura e mobilização da comunidade interna e externa à Universidade.

\section{METODOLOGIA}

O projeto de extensão para desenvolvimento de uma aplicação web para Escola de Música "O Som do Cerrado" foi realizado no ano de 2019, na e contou com a participação voluntária de três estudantes de graduação. Dois discentes do curso de Sistemas de Informação trabalharam no desenvolvimento full stack da aplicação web, ou seja, trabalharam com a programação da aplicação (back-end) e com a criação de telas obedecendo aos critérios de usabilidade (front-end) (NIELSEN E LORANGER, 2007). A identidade visual foi criada por um discente do curso de Agronomia, que também participa da Escola de Música. As etapas do projeto são sumarizadas na Figura 1.

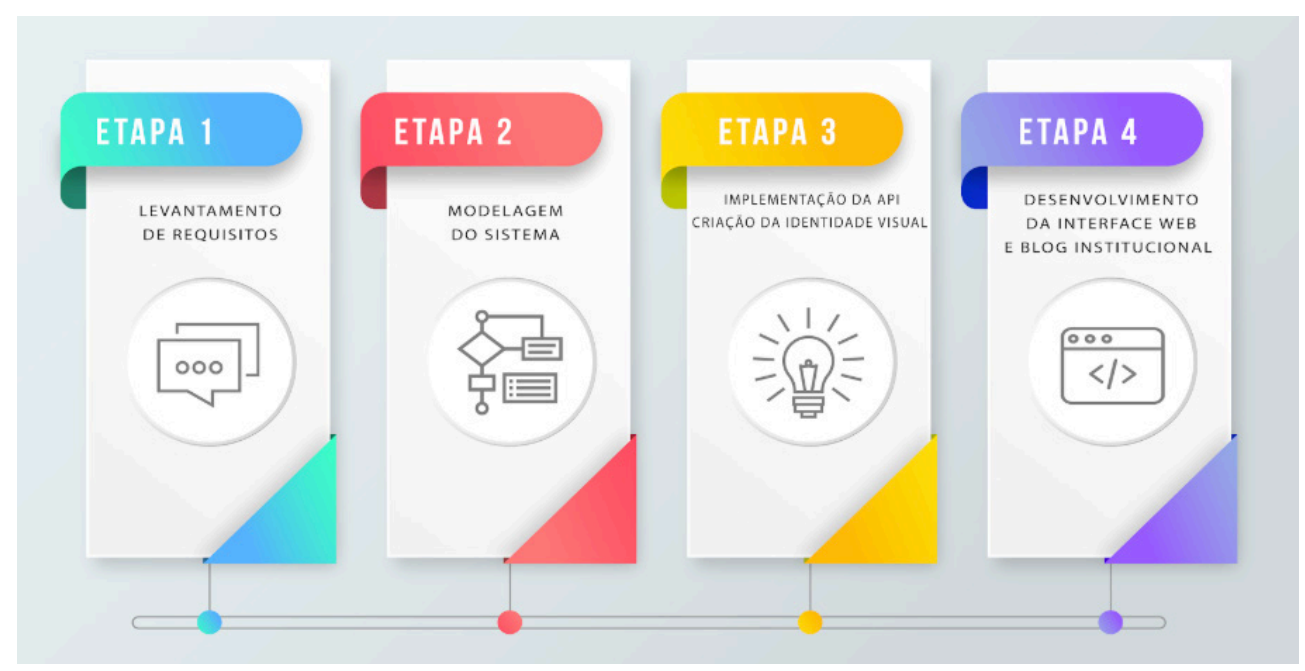

Figura 1: Etapas neCeSsárias para eXeCução do projeto. Fonte: Próprios Autores.

O início do projeto foi marcado por uma reunião com os membros da Escola de Música "O Som do Cerrado". Nesta ocasião foi aprovado o Termo de Abertura de Projeto (TAP), documento que formaliza o início do projeto (ROSE, 2013). O TAP apresenta o objetivo do projeto evidenciando o quão específico, mensurável, atingível e realista ele é. Além disso, definiu-se as premissas, a equipe de desenvolvimento, o escopo, o cronograma, restrições, riscos e requisitos necessários para aplicação web funcionar adequadamente.

Após a aprovação do TAP, realizou-se a primeira etapa denominada levantamento de requisitos. Nesta etapa foram definidos todos os requisitos necessários 
para que a aplicação web possa atender as necessidades dos usuários, quais funcionalidades devem ser implementadas e as restrições para que a aplicação seja desenvolvida. Para isso foram seguidos quatro passos: i) estudo de viabilidade; ii) levantamento e análise de requisitos; iii) documentação; e iv) validação dos requisitos. O levantamento de requisitos foi feito por meio de entrevistas com os membros da Escola de Música "O Som do Cerrado".

Após o levantamento dos requisitos, na segunda etapa, realizou-se a modelagem do sistema utilizando o diagrama de caso de uso presente na especificação Unified Modeling Language ( $U M L$ ), que utiliza atores e relacionamentos entre os mesmos para permitir a visualização e a compreensão da aplicação web como um todo, apresentando uma visão externa de como esses elementos podem ser utilizados dentro de um determinado contexto e quais são os seus comportamentos (GUEDES, 2018). Realizou-se também a modelagem do banco de dados que foi criado no Sistema Gerenciador de Banco de Dados MySQL, por meio da ferramenta de modelagem Workbench.

Definidos os requisitos e criado o modelo da aplicação web, realizou-se a prototipação das telas da aplicação web, sendo que a prototipagem das telas representa uma forma hábil e de menor custo para se definir o projeto. Além disso, a técnica de prototipagem serve como mecanismo para identificação dos requisitos de software e que também facilita a visualização do sistema que se deseja implementar (PRESSMAN, 2016).

Após a criação dos protótipos, iniciou-se a terceira etapa que consiste na implementação da API (Interface de Programação de Aplicação) para a aplicação web baseada em ferramentas gratuitas, as quais trazem inúmeras vantagens como: liberdade de integração com outros sistemas, redução de custos com licença de software e suporte de uma ampla comunidade.

Foi utilizada a linguagem de programação JavaScript, o mecanismo de tempo de execução Node e os módulos Express para o gerenciamento de rotas, Sequelize para o gerenciamento do banco de dados a partir da linguagem de programação JavaScript, GraphQL para modelar a API e Node Mailer para o envio de e-mails. Nesta etapa, também, foi elaborada a identidade visual considerando os elementos visuais que comunicam os valores da Escola de Música "O Som do Cerrado".

Por fim, na quarta etapa, foi desenvolvida uma interface web e um blog institucional para divulgação das atividades extensionistas realizadas pela escola de música, considerando a linguagem de marcação de texto HTML5, a linguagem de estilo CSS3, a linguagem de programação JavaScript e o framework de construção de interfaces a partir de componentes reativos React. Vale ressaltar que todas as etapas do desenvolvimento da aplicação web foram baseadas no SCRUM 
(SCHWABER, 2004) e Kanban (ANDERSON, 2019), escolhidas porque possibilitam adaptabilidade, agilidade, eficiência e feedback contínuo, o que resulta em melhorias progressivas em cada entrega do projeto.

\section{RESULTADOS}

Nesta seção são descritos os resultados alcançados com a execução do projeto de extensão para apoiar as atividades extensionistas da Escola de Música "O Som do Cerrado". Para o desenvolvimento da aplicação web foram abordadas as etapas que incluem criação da identidade visual, modelagem e implementação da aplicação web.

A identidade visual da Escola de Música "O Som do Cerrado" foi elaborada de acordo com o conjunto de elementos visuais que comunicam e representam os valores da escola, bem como a definição das cores, tipografia, formas e símbolos. Para isso, foi desenvolvido um logo que posiciona a Escola de Música "O Som do Cerrado" de forma imediata, clara e precisa. O logo traz o nome da escola de música em uma fonte estilo caligráfica, representando a arte e cultura. O ipê amarelo junto a uma partitura musical simboliza a origem e atividades realizadas na Escola de Música, pois assim como o ipê amarelo é nativo do cerrado, a Escola de Música está localizada nessa mesma região.

A Figura 2 mostra a logo desenvolvida, a qual é utilizada em todos os documentos gerados, apresentações e na divulgação de eventos e atividades extensionistas realizadas pela Escola de Música em mídias digitais.

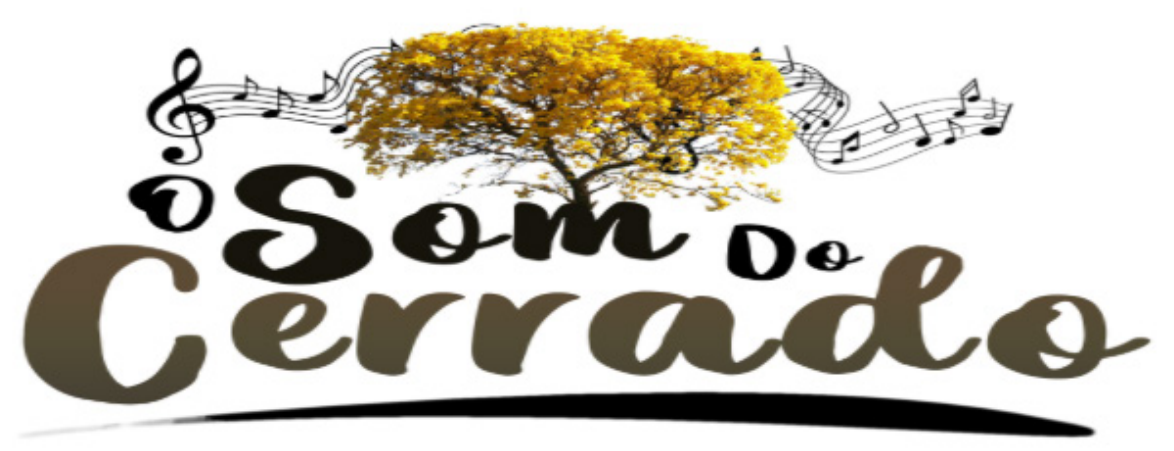

Figura 2: Loco desenvolvido para Escola de Música. Fonte: Próprios Autores.

A aplicação web desenvolvida consiste basicamente em três módulos: administrativo, público e servidor. Os dois módulos de interação por parte dos usuários 
são: Público, que representa a aplicação pública apresentada aos usuários (professor e estudante), e o módulo Administrativo, que é a aplicação em que os usuários administradores gerenciam as atividades da Escola de Música e todos os seus componentes relativos, além dos próprios usuários. As duas aplicações interagem com o servidor via API, para realizar buscas e manipular os dados.

As funcionalidades da aplicação web decorrentes do levantamento de requisitos realizado pode ser analisada pela ótica de projeto de software. As funcionalidades são: (1) Gerenciar usuários; (2) Gerenciar classes (turmas); (3) Gerenciar cursos; (4) Gerar progresso; (5) Registrar faltas; (6) Realizar curso; e (7) Pesquisar cursos, alunos e professores. A seguir são destacados os requisitos funcionais da aplicação web.

- Realizar Autenticação (Login): esse caso de uso permite o usuário autenticar-se no sistema para que as funcionalidades sejam liberadas. Prioridade: Essencial.

- Criar Conta (Sign up): esse caso de uso permite o usuário criar uma conta para poder autenticar-se ao sistema. Prioridade: Essencial.

- Gerenciar usuários: esse caso de uso permite que o usuário gerencie os usuários da Escola de Música (alunos e professores). Os usuários possuem um número de matrícula que é usado para sua identificação. Prioridade: Essencial.

- Gerenciar classes (turmas): no início de cada período letivo são formadas classes (turmas) para o estudo de teoria e prática musical de variados instrumentos musicais. Esse caso de uso permite ao usuário gerenciar as classes (turmas) disponíveis em um determinado período letivo. Prioridade: Essencial.

- Gerenciar cursos: são oferecidos cursos de teoria e prática de variados instrumentos musicais e o usuário deve gerenciar as classes (turmas) disponíveis. Prioridade: Essencial.

- Gerar progresso: esse caso de uso permite que o usuário visualize o progresso do aluno no curso em que ele está matriculado. Prioridade: Essencial.

- Registrar faltas: após cada aula lecionada devem ser lançadas as faltas dos alunos que estiveram ausentes. Cada curso exige uma frequência igual ou superior a $75 \%$. Prioridade: Essencial.

- Realizar curso: o usuário realiza a matrícula dos alunos em um curso específico, sendo que cada aluno possui um número de identificação. Prioridade: Essencial.

- Pesquisar cursos, alunos e professores: esse caso de uso permite que os usuários realizem pesquisas no sistema e verifiquem a quantidade de alunos matriculados, cursos disponíveis e professores de cada turma. Prioridade: Essencial.

Além dos requisitos funcionais descritos acima, a aplicação web conta com seguintes requisitos suplementares:

- Armazenamento de Dados: a camada de persistência é implementada de forma que diferentes tecnologias de bancos de dados possam vir a ser utilizadas no futuro. 
- Restrição de Acesso: o sistema contém áreas de acesso comum e restrito por meio de login e senha. Cada usuário tem acesso a informações que seu perfil necessita para realizar suas atividades, sendo impedido de acessar as demais. Os perfis de usuário são: 1) administrador; 2) professor; e 3) aluno.

- Realização de backups: o sistema não é crítico, porém é importante a realização de backups periódicos.

- Interface: o sistema é uma aplicação web e contém interfaces como formulários acessíveis em um navegador web.

Por fim, a aplicação web foi implementada considerando confiabilidade, portabilidade, desempenho e usabilidade (SOMERVILLE et al, 2007).

Para uma melhor compreensão das funcionalidades da aplicação web, a Figura 3 apresenta o diagrama de caso de uso que permitirá a exploração das funcionalidades em nível de projeto (GUEDES, 2018).

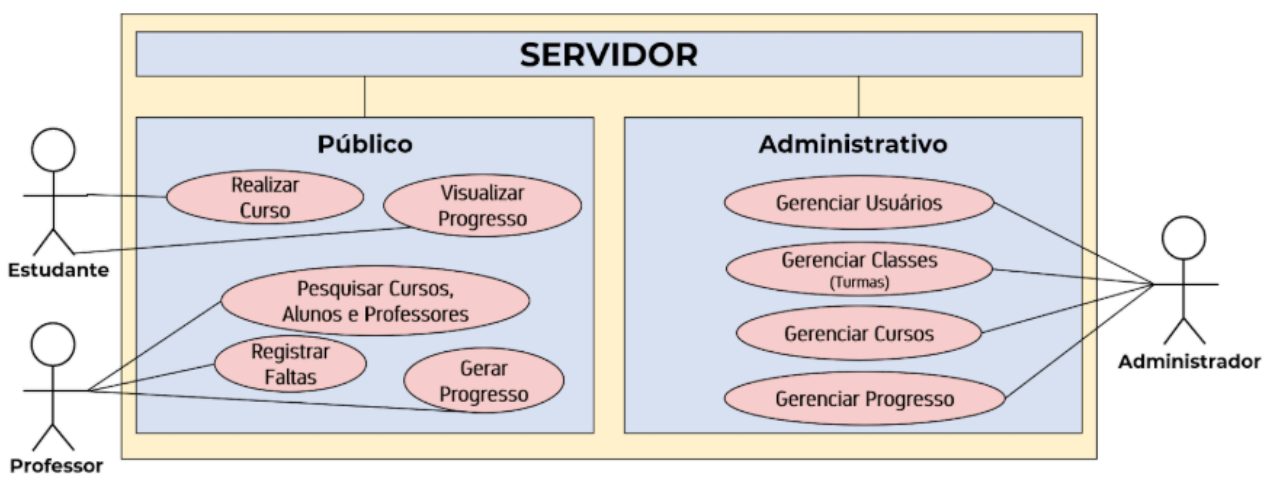

Figura 3: Diagrama de Caso de uso da AplicaÇão Web. Fonte: Próprios Autores.

De acordo com os requisitos levantados, foi feita a modelagem do banco de dados. A aplicação proposta é composta por dez entidades, ou seja, cada entidade é um objeto envolvido no domínio de negócios e apresenta características (atributos) e como se relacionam com outras entidades. A Figura 4 abaixo mostra o resultado da modelagem feita através da ferramenta Workbench.

Com base no modelo relacional, é possível observar a relação entre as entidades presentes no sistema, sendo que a entidade User atua como uma proteção de manipulação das demais entidades, ou seja, é necessário que tenha acesso ao sistema para cadastrar, editar ou excluir qualquer registro. Entretanto, antes de realizar tais operações, verifica-se qual o escopo que o usuário está associado (administrador, professor ou aluno). 


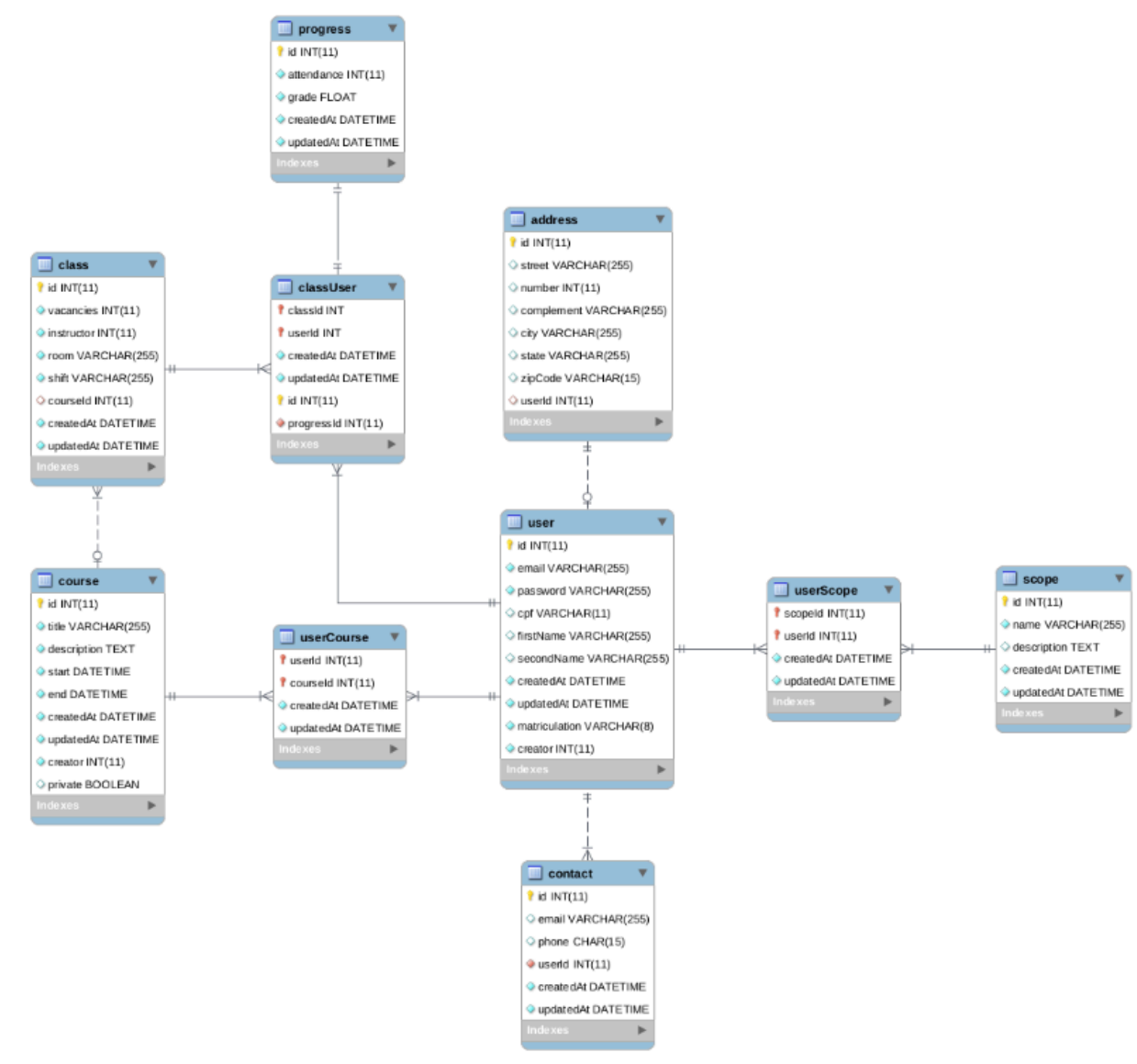

Figura 4: Modelo Relacional da AplicaçÃo Web. Fonte: Próprios Autores.

Do ponto de vista dos recursos físicos e de infraestrutura, para a totalidade dos encontros de extensão foi utilizado o BYOD (Bring Your Own Device), no português 'traga o seu próprio dispositivo', uma ação pensada para mostrar ao mesmo tempo que os seus próprios dispositivos móveis podem ser a chave para as atividades a serem desenvolvidas em suas aulas, para que baixassem (ou aprendessem a baixar) alguns dos aplicativos citados durante a extensão que lhes interessasse, para que conhecessem melhor seus aparelhos de smartphone (ou tablet) e se sentissem mais confiantes para usá-lo para fins acadêmicos, além de conhecermos melhor seus níveis de aprofundamento tecnológico.

Dados apresentados pela pesquisa TIC Educação 2018 ${ }^{7}$, da Cetic.br, mostraram que naquele ano $51 \%$ dos professores acessaram a internet de seu próprio celular para desenvolver atividades em sala de aula com seus alunos. A proposta do curso foi um sucesso e nos confirmou, na prática e através dos dados divulgados recentemente, o potencial deste tipo de método. 
Neste caso, o usuário do tipo administrador possui acesso amplo dentro da aplicação, salvas limitações existentes no modelo, como mostra a Tabela 1.

TABELA 1. DESCRIÇÃO DE POSSÍVEIS AÇÕES DO ADMINISTRADOR

\begin{tabular}{l|l}
\multicolumn{1}{|c|}{ AÇÃO } & \multicolumn{1}{c}{ DESCRIÇÃO } \\
\hline Gerenciar Usuários & $\begin{array}{l}\text { Cadastrar ou excluir usuários, além de poder alterar a } \\
\text { própria senha. }\end{array}$ \\
\hline Gerenciar Classes (turmas) & Cadastrar, alterar ou excluir turmas ativas. \\
\hline Gerenciar Cursos & $\begin{array}{l}\text { Cadastrar, alterar ou excluir cursos, desde que estes não } \\
\text { estejam associados a pelo menos uma turma ativa. }\end{array}$ \\
\hline Gerenciar Progresso & Pesquisar cursos, classes e visualizar progresso \\
\hline
\end{tabular}

Fonte: PRÓPRIOS AUTORES.

Por outro lado, os demais usuários (professor e aluno) possuem acesso mais restrito podendo realizar apenas as ações mencionadas na Tabela 2.

TABela 2. DESCRIÇÃO dE POSSÍVEIS AÇÕES DO ADMINISTRADOR

\begin{tabular}{l|l}
\multicolumn{1}{c}{ ATOR } & \multicolumn{1}{c|}{ AçÃo } \\
\hline Professor & $\begin{array}{l}\text { Gerenciar progresso dos alunos, gerar lista de presença, } \\
\text { registrar faltas e visualizar alunos e cursos. }\end{array}$ \\
\hline Aluno & Visualizar curso e visualizar progresso. \\
\hline
\end{tabular}

Fonte: PRÓPRIOS AUTORES.

A implementação da aplicação web foi realizada seguindo a metodologia descrita na seção anterior e utiliza design responsivo, ou seja, foi projetada para ser adaptada a qualquer tipo de resolução ou dispositivo. A aplicação web encontra-se disponível para a comunidade em e as principais telas são apresentadas a seguir.

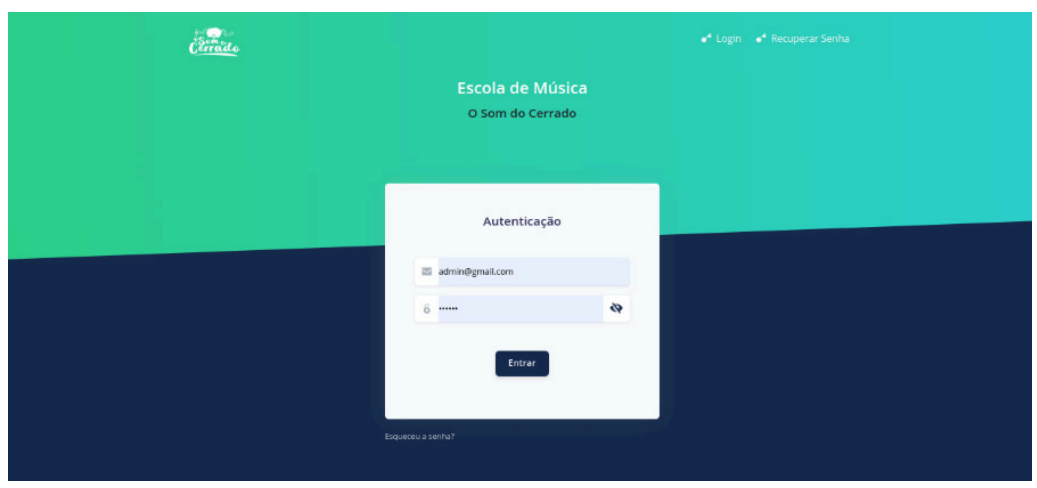

Ficura 5: Tela de autenticaçÃo da aplicaçÃo Web. Fonte: Próprios Autores. 
Conforme ilustra a Figura 5, todos os usuários da aplicação são cadastrados de forma similar, diferenciando-se pelo papel exercido por cada um dentro da aplicação. Isso significa que cada usuário tem diferentes níveis de permissão dentro da aplicação, ou seja, regras são aplicadas e implicam diretamente no que cada usuário pode e o que não pode fazer dentro da aplicação, sendo essas ações atreladas às manipulações das entidades resultantes da modelagem do banco de dados.

O cadastro de usuários é feito somente por algum usuário com perfil administrador. Por exemplo, após realizar matrícula, o aluno é cadastrado na aplicação web por um usuário com perfil de administrador. Com o cadastro realizado, o aluno tem acesso aos cursos oferecidos, pode se matricular em alguma turma e acompanhar seu progresso no curso.

Após se autenticar no sistema, o usuário (administrador, professor ou aluno) é redirecionada para a página inicial denominada dashboard, como ilustra as Figuras 6 e 7. Conforme descrito anteriormente, cada usuário apresenta diferentes níveis de acesso ao sistema o que resulta em um dashboard específico para cada usuário.

Além das operações básicas (criar, atualizar, listar e excluir), a aplicação web também permite visualizar índices de notas médias em cada curso, frequência dos alunos e cursos que estão sendo oferecidos, conforme visto na Figura 7.

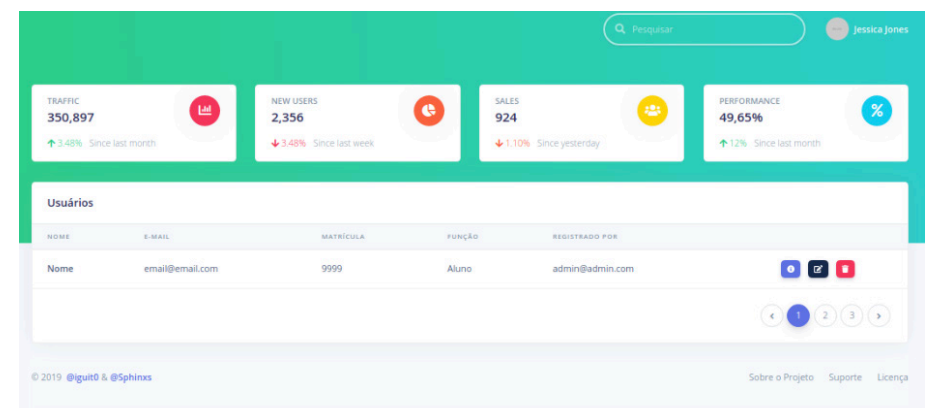

Figura 6: Dashboard presente na aplicação Web. Fonte: Próprios Autores.

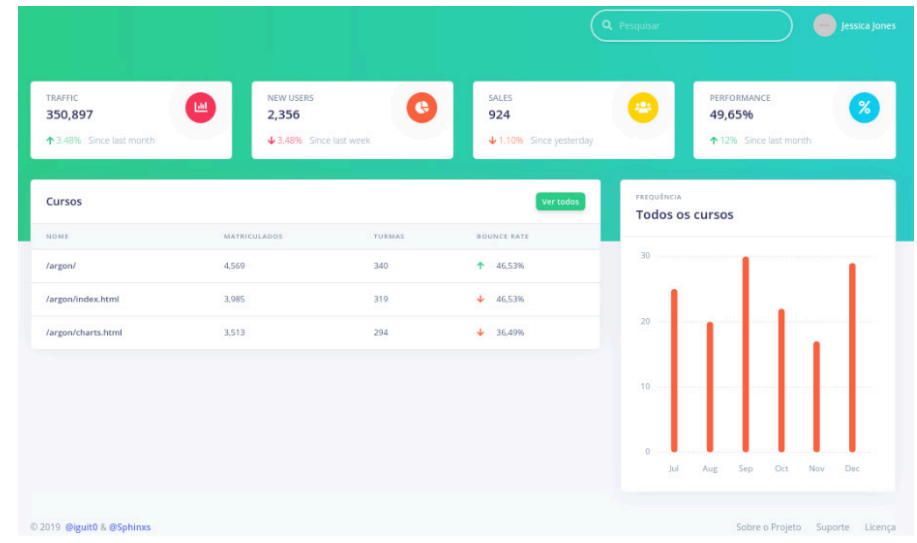

Figura 7: Tela com informações sobre os CuRsos. Fonte: Próprios Autores. 
Vale ressaltar que todas as telas foram construídas considerando as questões relacionadas à usabilidade, atributo de qualidade que se relaciona com a facilidade que deve existir ao usar o sistema. Neste trabalho, levou-se em consideração as dez heurísticas de Nielsen, que é o método mais utilizado para quaisquer tipos de interface (DIX et al. 2003; NIELSEN E LORANGER, 2007; NIELSEN E BUDIU, 2013). Sendo que durante todo o desenvolvimento a equipe preocupou-se em manter a consistência e padronização das telas, com o intuito de facilitar o uso do sistema e, também, tornar a experiência do usuário mais interessante. Além disso, a prevenção de erros foi devidamente aplicada em todas as etapas da implementação. Para isso, a qualidade do código foi analisada com as ferramentas gratuitas: Codacy, CircleCI e Code Climate.

Dentro do aspecto tecnológico adotado neste trabalho, é possível observar que o desenvolvimento de aplicações por completo pode ser feito considerando a variedade de recursos presentes no surgimento de novas tecnologias para desenvolvimento web. Além disso, o desenvolvimento full-stack possibilitou a entrega de uma solução robusta e de qualidade, sendo que a aplicação começa a ser utilizada integralmente a partir de 2020.

Aliar a tecnologia com a atividade extensionista resulta para a Escola de Música "O Som do Cerrado" vantagens que vão desde a modernização até uma ampla divulgação, permitindo que a cultura musical ultrapasse as fronteiras da Universidade. Além disso, questões de sustentabilidade são contempladas porque a substituição de documentos em papel para documentos em meio digital, geram economia e preservação ambiental.

Por fim, vale a pena ressaltar que o presente projeto está alinhado com as diretrizes estratégicas estabelecidas pela Universidade. Exemplo disso é a missão da instituição apresentada no Plano de Desenvolvimento da Instituição (PDI) 20182023: "Promover, por meio de ações integradas de ensino, pesquisa e extensão, o avanço das ciências, letras e artes, a excelência, a inovação, o desenvolvimento institucional, a formação de cidadãos com visão técnica, científica e humanística." O projeto também segue e colabora com o que foi previsto no Plano Diretor de Tecnologia da Informação (PDTI) da, em que é determinado como missão "planejar e executar a política de tecnologia da informação e comunicação, de forma a desenvolver e manter os sistemas de informação e a infraestrutura corporativa de software e hardware, visando à melhoria da eficiência nas atividades, de ensino, pesquisa, extensão e gestão administrativa." 


\section{CONCLUSÃO}

Este trabalho permitiu a interação entre atividades de pesquisa, ensino e extensão. A pesquisa foi realizada com o intuito de levantar e analisar todos os requisitos necessários para o desenvolvimento da aplicação web. O resultado deste estudo é importante, pois a informatização da Escola de Música "O Som do Cerrado" favoreceu a ampliação e divulgação das atividades extensionistas realizadas.

$\mathrm{O}$ uso de ferramentas gratuitas, modernas e amplamente utilizadas no mercado contribuiu com o ensino, uma vez que o uso de tais ferramentas agregou conhecimento e experiência para os discentes participantes do projeto de extensão.

Por fim, a extensão pode ser vista pela junção do conhecimento adquirido a partir da pesquisa, treinamento e a disponibilização das informações para a melhoria do projeto de extensão da Escola de Música "O Som do Cerrado".

Os próximos passos deste trabalho consistem em: realizar um estudo de caso, no início do período letivo de 2020, para avaliar a usabilidade da aplicação web e, também, aplicar técnicas de mineração de dados para avaliar o quanto a divulgação online por meio do site institucional gerou oportunidades de expansão das atividades extensionistas de arte e cultura.

\section{REFERÊNCIAS}

ANDERSON, David J. Kanban: successful evolutionary change for your technology business. Blue Hole Press, 2010.

DA CUNHA, Andréia Borges. Música e sociedade: a importância da música no âmbito social. Integratio, v. 2, n. 2, p. 17-21, 2016.

DIX, Alan. Human-computer interaction. Springer US, 2009.

GUEDES, Gilleanes TA. UML 2-Uma abordagem prática. Novatec Editora, 2018.

HALLAM, S. The power of music: its impact on the intellectual, personal and social development of children and young people. U: S. Hallam i A. Creech (ur.). Music Education in the 21st Century in the United Kingdom, p. 2-17, 2010. 
IWASAKI, Yoshitaka; COYLE, Catherine P.; SHANK, John W. Leisure as a context for active living, recovery, health and life quality for persons with mental illness in a global context. Health promotion international, v. 25, n. 4, p. 483-494, 2010.

LAURINDO, Fernando José Barbin et al. O papel da tecnologia da informação (TI) na estratégia das organizações. Gestão \& Produção, v. 8, n. 2, p. 160-179, 2001.

MAWANG, Lucy Lugo; KIGEN, Edward M.; MUTWELELI, Samuel M. The relationship between musical self-concept and musical creativity among secondary school music students. International Journal of Music Education, v. 37, n. 1, p. 78-90, 2019.

NIELSEN, Jakob. 10 usability heuristics for user interface design. Nielsen Norman Group, v. 1, n. 1, 1995.

NIELSEN, Jakob; BUDIU, Raluca. Mobile usability. MITP-Verlags GmbH \& Co. KG, 2013.

NIELSEN, Jakob; LORANGER, Hoa. Usabilidade na web. Elsevier Brasil, 2007.

PRESSMAN, Roger; MAXIM, Bruce. Engenharia de Software-8 ${ }^{\text {a }}$ Edição. McGraw Hill Brasil, 2016.

ROSE, Kenneth H. A Guide to the Project Management Body of Knowledge (PMBOK ${ }^{\oplus}$ Guide) - Fifth Edition. Project management journal, v. 44, n. 3, p. e1-e1, 2013.

SCHWABER, Ken. Agile project management with Scrum. Microsoft press, 2004.

SCHMIDT, Charles P. Relations among motivation, performance achievement, and music experience variables in secondary instrumental music students. Journal of Research in Music Education, v. 53, n. 2, p. 134-147, 2005. 
SOMMERVILLE, Ian. Engenharia de Software, $8^{\text {a }}$ edição. Pearson, Addison Wesley, v. 8, n. 9, p. 10, 2007.

SPYCHIGER, Maria; GRUBER, Lucia; OLBERTZ, Franziska. Musical Self-Concept-Presentation of a Multi-Dimensional Model and Its Empirical Analyses. In: ESCOM 2009: 7th Triennial Conference of European Society for the Cognitive Sciences of Music. 2009. 